\title{
Comparative study of conventional papanicolaou smears and liquid based direct-to- vial thin-layer preparation in the detection of microorganisms in cervical smears
}

\author{
Suma Kaza ${ }^{1}$, I. V. Renuka, ${ }^{2, *}$ Lakshmi Kantham ${ }^{3}$, Swapna Srinath ${ }^{4}$, Ramesh Babu $^{5}$ \\ ${ }^{1}$ Consultant, ${ }^{2}$ Senior Consultant Pathologist, ${ }^{1,2}$ Dept. of Pathology, Ramesh Hospitals, Guntur, Andhra Pradesh, ${ }^{3}$ Senior \\ Consultant, ${ }^{4}$ Consultant, ${ }^{3,4}$ Dept. of Gynaecology, Ramesh Hospitals, Guntur, Andhra Pradesh, Medical Director and Senior \\ Consultant, Dept. of Cardiology, Ramesh Hospitals, Guntur, Andhra Pradesh, India
}

*Corresponding Author:

Email: repriya56@gmail.com

\begin{abstract}
Introduction: In addition to its primary benefit as a cancer screening test, other benefits of Pap test include detection of cervicovaginal microorganisms. Very few studies have been performed in our country to compare Liquid based cytology (LBC) and Conventional papanicolaou smear (CPS) for detection of cervicovaginal infection by microorganisms.

Materials and Methods: Our study focuses on non neoplastic findings which correlate to the presence of MicroorganismsTrichomonas Vaginalis, Candida Species, Bacterial Species, Actinomycosis Species, and Herpes simplex virus. Papanicolaou smear by conventional and liquid based cytology have been used to study effectiveness of each method in diagnostic cytology. A comparative prospective study from March 2017 to May 2017 of 45 split samples for comparing effectiveness of liquid based Thin-layer preparation with that of conventional papanicolaou (Pap) smears to demonstrate microorganisms in cervicovaginal smears was undertaken. These two methods have been compared for reporting the presence of microorganisms, essential for a complete diagnostic evaluation of cervicovaginal specimens by the 2001 Bethesda system under the specific category of "Organisms".

Results: Altered Flora (AF) Bacterial Vaginosis (BV) in CPS and by LBC were reported. Candidal infection, Trichomonas infection and Leptothrix were compared in CPS and LBC preparations.

The comparison showed that Candidal hyphae were more easily seen on LBC while the Candidal yeast forms are more easily detected on CPS. Trichomonas \& shift of vaginal flora are detected more easily on CPS than on LBC preparations.

Conclusion: Our findings suggest utility of both methods for the detection of microorganisms commonly seen in cervical cytology practice.
\end{abstract}

Keywords: Papanicolaou, Smear, organisms, Bethesda, Liquid based.

\section{Introduction}

Papanicolaou smear has been used for more than 50 years. ${ }^{1}$ Since 1994 cervicovaginal surveys related to implementation of the Bethesda System terminology and reporting rates for interpretive categories are used in papanicolaou testing. ${ }^{2}$ The 2001 Bethesda system reporting terminology includes the category of "Organisms" as part of the "nonneoplastic" findings. The microorganisms included are: Trichomonas Vaginalis, Candida species, Bacterial species, Actinomyces species and Herpes simplex virus. ${ }^{3}$

Obscuring inflammation was the second most common reason for unsatisfactory CPS while foreign material or lubricant for LBC in the 2007 College of American Pathologists supplemental questionnaire survey. $^{2}$

Comparing CPS and LBC, the background is virtually eliminated in SurePath ${ }^{\mathrm{TM}}$. So to identify a shift in bacterial flora was defined by the sole presence of clue cells (squamous cells covered by a layer of coccobacilli gardnerella vaginalis that obscure the cell membrane). So CPS is friendlier towards detection of Bacterial Vaginoses.

Trichomonas organisms range from 4-32 um so they may be eliminated in SurePath ${ }^{\mathrm{TM}}$ processing steps. SurePath $^{\mathrm{TM}}$ claims to decrease the number of neutrophils which are comparable to the size of few trophozoites. But partial elimination may make LBS less effective than CPS for detecting Trichomonas.

Candida organisms are much larger than Trichomonas and Bacteria and are therefore not eliminated in the SurePath ${ }^{\mathrm{TM}}$ processing. In addition, Sedimentation step provides an increase in concentration of fungal organisms compared with CPS. So LBC is more effective than CPS for detection of Candidal organisms. ${ }^{2}$

LBC preparation methods have been found to outperform CPS in the detection of low grade and high grade cytologic lesions. ${ }^{4}$ To the best of our knowledge this is the first split - sample study in our part of the country, to compare diagnostic utility of LBC \& CPS for detecting microorganisms as part of non-neoplastic findings in the Cervicovaginal cytology as per the Bethesda System.

\section{Materials and Methods}

The present study was conducted, in the departments of Gynecology \& Obstetrics and Pathology. Conventional Pap smear and Surepath specimens were collected separately from 45 patients by direct-to-vial method. Informed consent for this study was taken orally from all patients. 
The conventional Pap smear samples were collected by qualified medical professional using a spatula.

Harvested cells were smeared on to the glass slide, fixed and sent to the lab for processing.

In the same sitting for liquid based cytology, a broom type sampling device was used to collect the cervicovaginal specimen by the same qualified medical professional. The head of the sampling device was placed into the SurePath ${ }^{\mathrm{TM}}$ collection vial which was capped labeled and sent with appropriate paperwork to the laboratory for processing. The broom was not used to prepare conventional smears therefore it was a directto-vial method. The head of the sampling device was never removed from the SurePath ${ }^{\mathrm{TM}}$ preservative vial during the entire preparation process.

The Prepstain slide processor converts the liquid suspension of a cervicovaginal cell sample into a discretely stained, homogenous thin layer of cells while maintaining diagnostic cell clusters.

The process includes cell preservation, randomization, enrichment of diagnostic material, pipetting, sedimentation, staining, and coverslipping to create a SurePath ${ }^{\mathrm{TM}}$ slide for use in routine cytology screening and categorization as defined by the Bethesda system.

Prepstain Preparation: The cell solution was transferred into Prepstain density reagent. An enrichment step comprised of centrifugal sedimentation through density reagent, partially removing nondiagnostic debris and excess inflammatory cells from the sample. After centrifugation, the pelleted cells were resuspended, mixed and transferred to a Prepstain setting chamber mounted on a microscope slide. The slides were coated by a Prepstain slide coat to enhance cell adhesion.

The cells were then sedimented by gravity, stained on the Prepstain slide processor using modified Pap- staining procedure, cleared with xylene and coverslipped.

SurePath $^{\mathrm{TM}}$ slide presents a well preserved population of stained cells present within a circle measuring $13 \mathrm{~mm}$ in greatest dimension.

Air-drying artifact and obscuring, overlapping cellular material and debris are largely eliminated. The numbers of leukocytes are significantly reduced, allowing for the easier visualization of epithelial cells, diagnostically relevant cells and infectious organisms.

The final diagnosis for both slide population was recorded electronically after studying each category of the Bethesda System.

The findings of the organisms category of Bethesda System have been tabulated and compared. Direct-tovial rather than split sample method which is less favorable to liquid based method was used.

The primary objective of the study is to compare if the SurePath ${ }^{\mathrm{TM}}$ slides are equivalent to or better than conventional Pap slides to detect various microorganisms seen in cervicovaginal smears.

\section{Result}

Pap smears from 45 women were studied in two methods by CPS and LBC between the ages of $23 y$ rs to $70 y r s$. The age wise distribution of the subjects is given in Table $1 \&$ Pie chart 1.

Table 1: Age wise distribution of the subjects

\begin{tabular}{|l|c|c|}
\hline S. No. & Age (yrs) & No. \\
\hline 1. & $20-29$ & 05 \\
\hline 2. & $30-39$ & 10 \\
\hline 3. & $40-49$ & 12 \\
\hline 4. & $50-59$ & 13 \\
\hline 5. & $60-69$ & 04 \\
\hline 6. & $\geq 70$ & 01 \\
\hline & Total & 45 \\
\hline
\end{tabular}

\section{Pie chart 1: Age wise distribution of subjects}

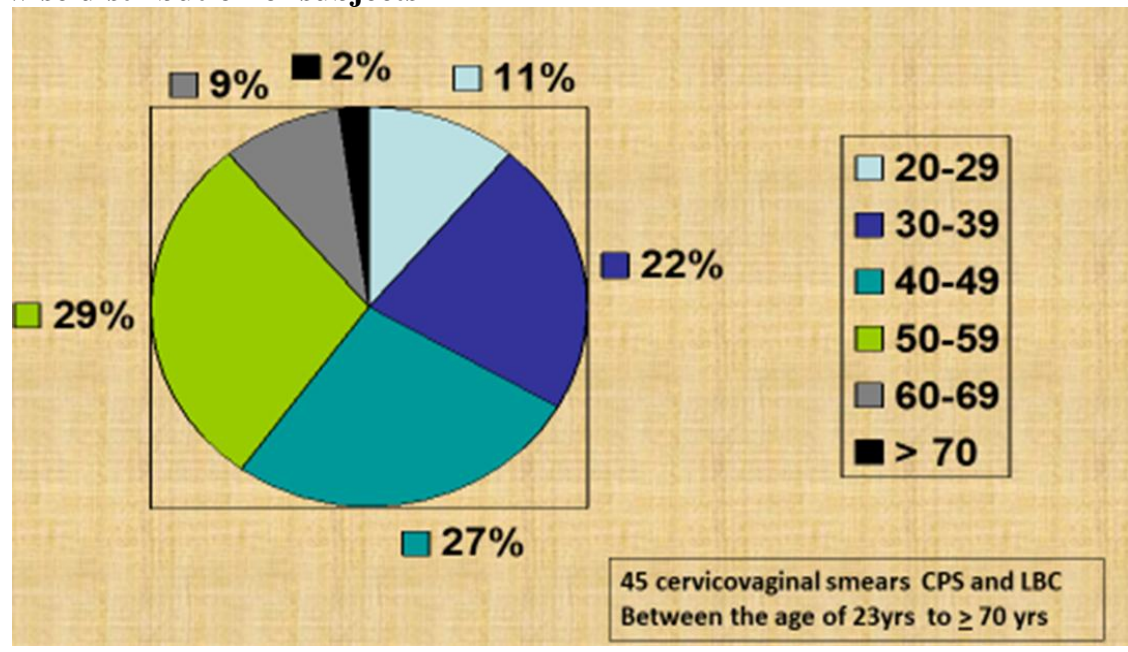


All 45 smears by both methods were found to be satisfactory for evaluation with approximate 5000 squamous cells or more in the LBC and 8000-12000 cells or more in CPS.
Maximum patients were in the 50-59 year bracket and lowest number were seen above 70 years. A comparison was made between CPS and LBC taking into consideration various epithelial abnormalities and organism. (Table 2) (Graph 1 )

Table 2: Comparison of smears in CPS \& LBC

\begin{tabular}{|l|c|c|c|c|c|}
\hline S. No. & Report & Conventional & LBC & CPS\% & LBC\% \\
\hline 1. & $\begin{array}{c}\text { Epithelial cell } \\
\text { abnormality (LSIL/HSIL) }\end{array}$ & 2 & 2 & 4.44 & 4.44 \\
\hline 2. & Unsatisfactory & 0 & 0 & 0 & 0 \\
\hline 3. & Normal & 20 & 16 & 44.44 & 35.56 \\
\hline 4. & Atrophic & 6 & 5 & 13.33 & 11.11 \\
\hline 5. & I / AF & 3 & 4 & 6.67 & 8.89 \\
\hline 6. & I / Candida & 4 & 6 & 8.89 & 13.33 \\
\hline 7. & I / Leptothrix & 0 & 1 & 0 & 2.22 \\
\hline 8 & BV & 9 & 7 & 20.00 & 15.56 \\
\hline 9 & BV + TV & 0 & 1 & 0 & 2.22 \\
\hline 10 & Actinomycosis & 0 & 0 & 0 & 0 \\
\hline 11 & TV & 1 & 2 & 2.22 & 4.44 \\
\hline 12 & HSV & 0 & 1 & 0 & 2.22 \\
\hline Total & & 45 & 45 & & \\
\hline
\end{tabular}

I : Inflammatory, AF: Altered Flora, BV : Bacterial Vaginosis; TV: Trichomonas Vaginalis; HSV : Herpes Simplex Virus

Graph 1: Comparison of various diagnoses between CPS and LBC

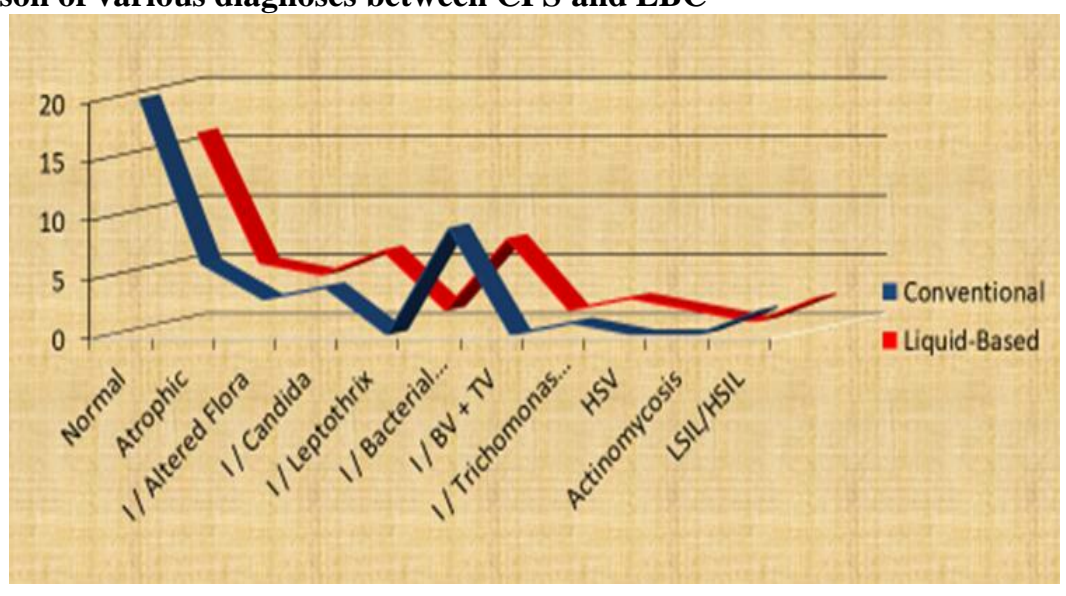

\section{Discussion}

The clinical and scientific allure of liquid based technology has been explored extensively. ${ }^{5}$ Most western countries have switched over from CPS to LBC, even though sensitivity and specificity is almost similar in various comparison studies. The reason for this may be consistently increased rates of satisfactory results for epithelial abnormalities on LBC, clarity of microscopy, improved sample processing, and small area to be screened. ${ }^{6}$

Liquid based cytology techniques are currently applied to cytological samples from several tissues or fluids other than uterine cervix. They include endometrium, aspirates from breast and thyroid tumors, ascitic and pleural effusions. ${ }^{7}$
Pap smears are routinely used for cervical cancer screening. In our study two cases of epithelial abnormality were detected in both CPS \& LBC and later confirmed by histopathology. Diagnosis

of inflammatory lesions like Bacterial Vaginosis is important as it can lead to pelvic inflammatory disease, preterm birth and Chorioamnionitis. ${ }^{8}$

Few reports have supported the fact that cytology is a valuable tool in the diagnosis and detection of cervical and vaginal infection. ${ }^{9}$

Women want a test that is reliable, accurate, and predictive and that ideally leads to as few questionable results and repeat testing as possible.

The promises of liquid based cytology include reduction of obscuring artifacts like RBC's, clumps of 
mucus, aggregates of "Polymorphonuclears", cellular overlap and air dried artifact.

The problem with conventional Pap smear is that $40 \%$ is compromised by artifacts. ${ }^{5}$ (Fig. $1 \& 2$ ).

In a study by Singh et $\mathrm{al}^{6} 0.14 \%$ slides were seen with Altered Flora (AF) and Bacterial Vaginosis (BV) in $0.13 \%$ slides in CPS method as compared to LBC where $\mathrm{AF}$ was $0.11 \%$ and $\mathrm{BV}$ was $0.11 \%$.

In our study $6.67 \% \mathrm{AF}, 20 \% \mathrm{BV}$ in $\mathrm{CPS}$ and 8.89\% AF and $15.56 \%$ BV by LBC were noted.

Atrophic smears in Singh et $\mathrm{al}^{6}$ study showed actinomycetes-like organisms, Leptothrix and Trichomonas Vaginalis (TV) in $0.17 \%$ of cases in CPS and 0.16 cases in LBC. ${ }^{6}$

In the present study one atrophic smear showed $\mathrm{TV}$ $2.22 \%$ in LBC preparations. However it has been observed that degenerated fragments of cytoplasm or macrophages can be mistaken for trichomonads, particularly in liquid based preparations. ${ }^{6}$

Candida spores were picked up more easily in CPS $(0.28 \%)$ and Candida hyphae were picked up more in LBC $(0.12 \%)$ in the Singh et al study. ${ }^{6}$
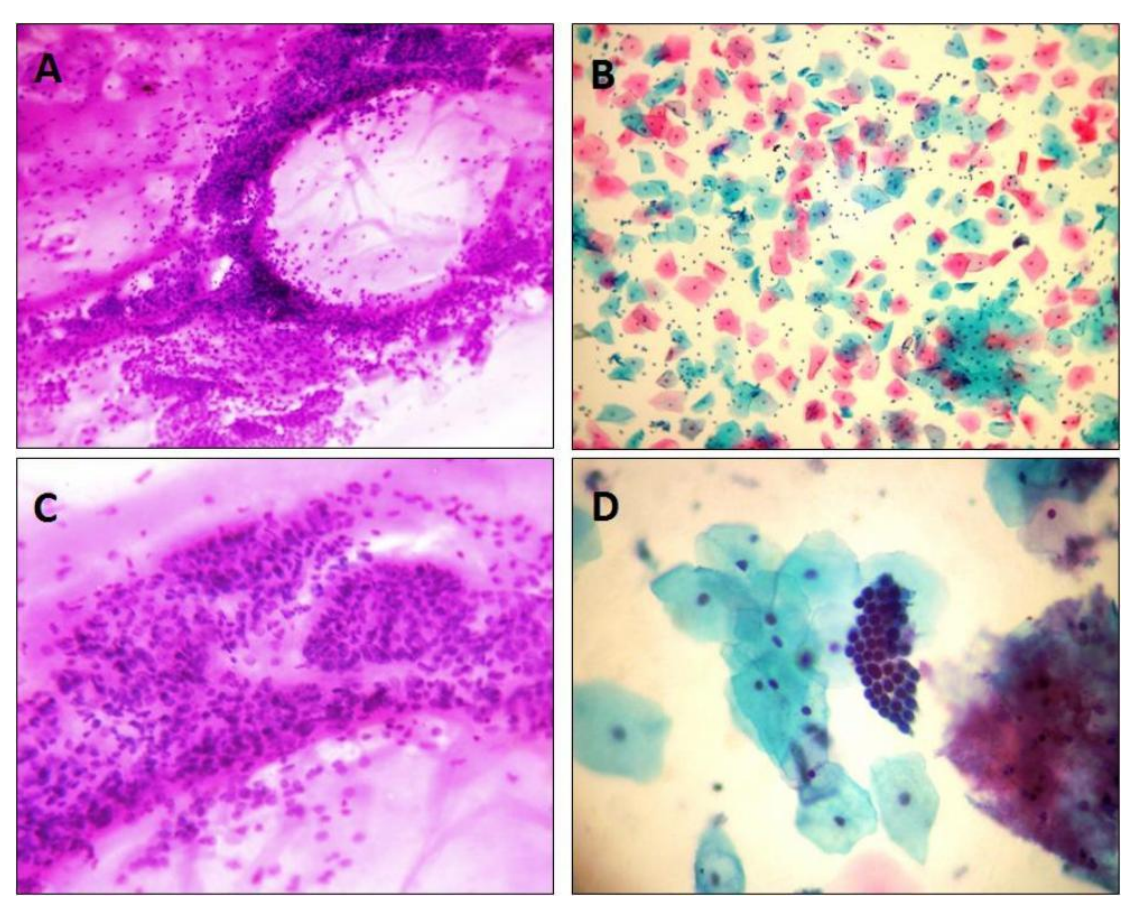

Fig. 1: (A) CPS: Inflammatory background (H \&E, x 100); (B) LBS: Clean background (Pap, x 400); (C) CPS: Endocervical clusters amidst Inflammatory background (H \& E, x 100); (D) LBS: Clearer honeycomb endocervical clusters (H\& E x 400)

Bukhari et al reported that Candida albicans was the commonest organism $6 \% .{ }^{10}$ In the present study Bacterial Vaginitis was the most frequent (15.56\%).

Sherwani et al reported Candida in $8.7 \%$ cases by LBC and $3.1 \%$ cases by CPS. ${ }^{11}$ We reported Candida in CBS $8.89 \%$ in LBC $13.33 \%$.

LBC Pap test results in a study by Levi et al revealed $13.9 \% \mathrm{BV}, 13.9 \%$ Candidiasis and $0.7 \%$ Trichomonas infection. $^{12}$

Bacterial Vaginitis in various studies geographically was Madhivanan et al (India) $19 \% ;^{13}$ Heller et al (USA) $2 \%^{14}$ and Romeran etal (Africa) $38 \%$. $^{15}$

Prevalence of Bacterial Vaginosis - 17\%, Vaginal Candidiasis - $11 \%$ and $0.4 \%$ Trichomonas Vaginalis was seen in a CPS study in Iran. ${ }^{16}$ In our study in CPS, $20 \%$ BV, Candidiasis - $8.89 \%$ and TV $-2.22 \%$ was reported. On the other hand our study in LBC showed BV - $15.56 \%$, Candidiasis- $13.33 \%$ and TV- $4.44 \%$, which is significantly different percentage for each category of organisms as compared to CPS. (Fig. $3 \&$ 4). Comparison of various studies with the present study is depicted in bar diagram $1 \& 2$. 

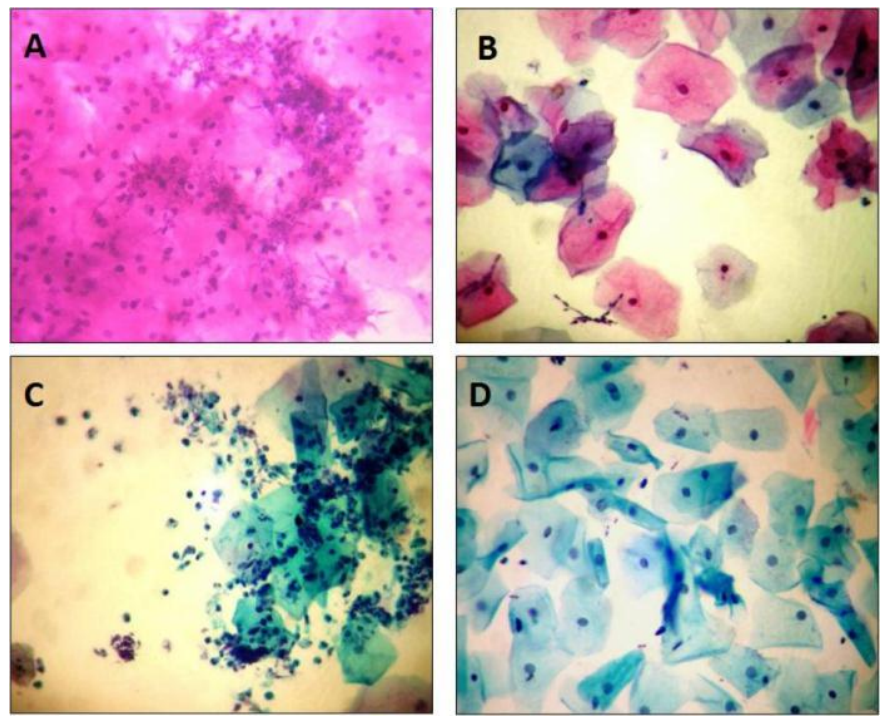

Fig. 2: (A) CPS: Obscured Pseudohyphae of Candida in inflammatory background (H \&E, $x$ 100); (B) LBS: Candidal pseudohyphae in a clean background (Pap, $x$ 400); (C) CPS camouflaged budding yeast forms of Candida (Pap, x 400); (D) LBC with a clear background and budding yeasts of candidal species (Pap, $x$ 400)

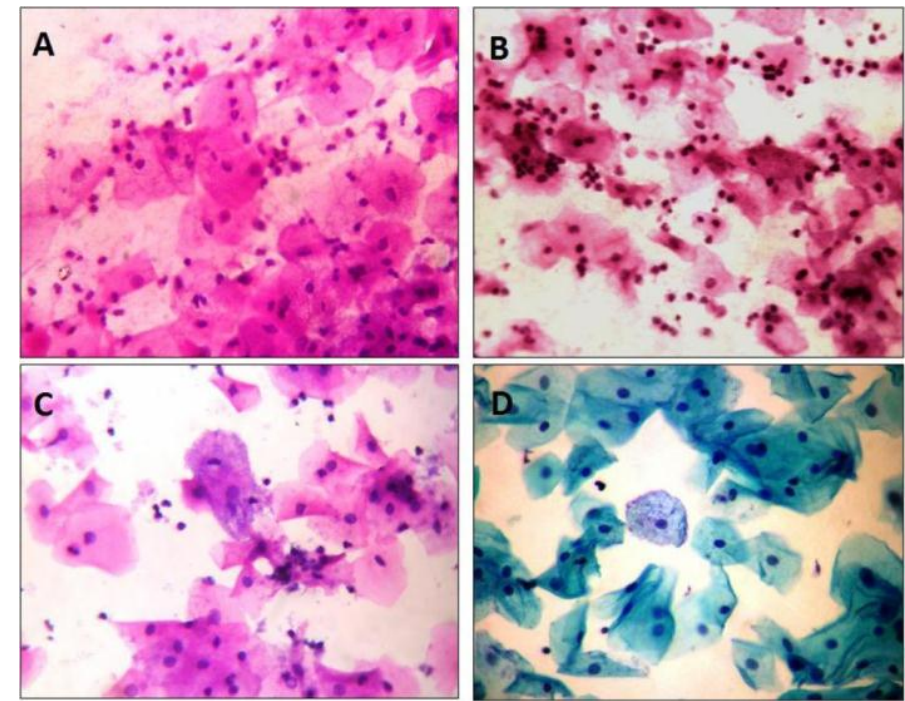

Fig. 3: (A) CPS showing trichomonal organisms with inflammatory background (H \&E, $x$ 100); (B) LBC with kite like Trichomonal Organisms in a clean background. (Pap, $x$ 400); (C) Clue cell in CPS (Pap x 400); (D) Clue cell in LBS. (Pap, $x$ 400)

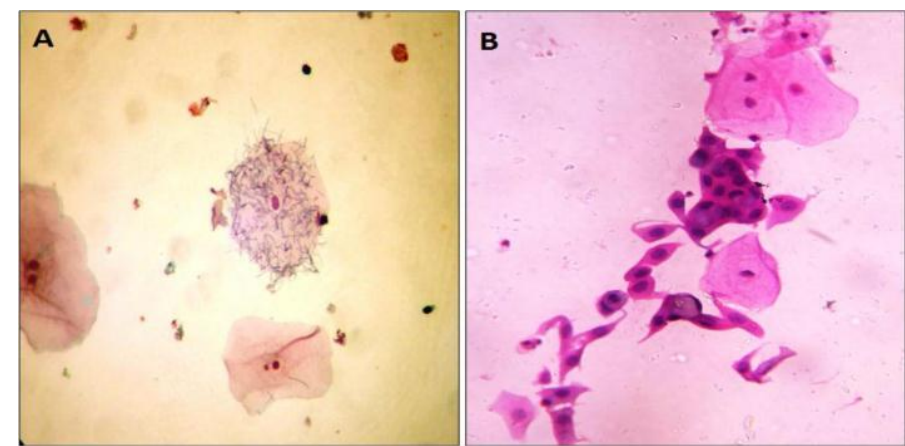

Fig. 4: (A) Leptothrix organisms in LBS (Pap, $x$ 400); (B) Frank ground glass nuclei in LBS indicating Herpes Simplex Virus Infection (Pap, x 400) 
Bar diagram 1: Comparison of various studies with the present study

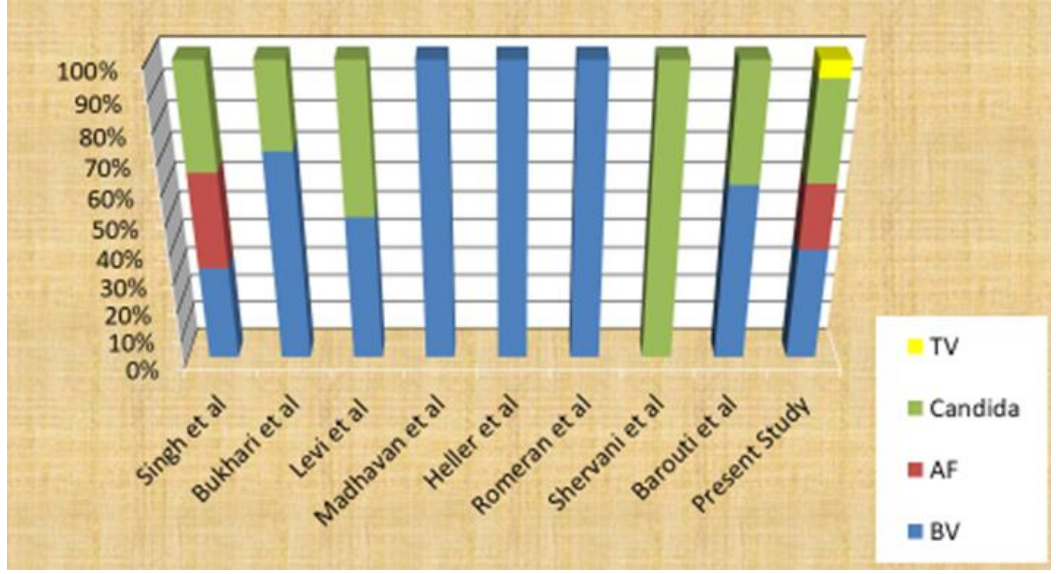

Bar diagram 2: Comparison of various studies with the present study in respect to Candidal and bacterial infection

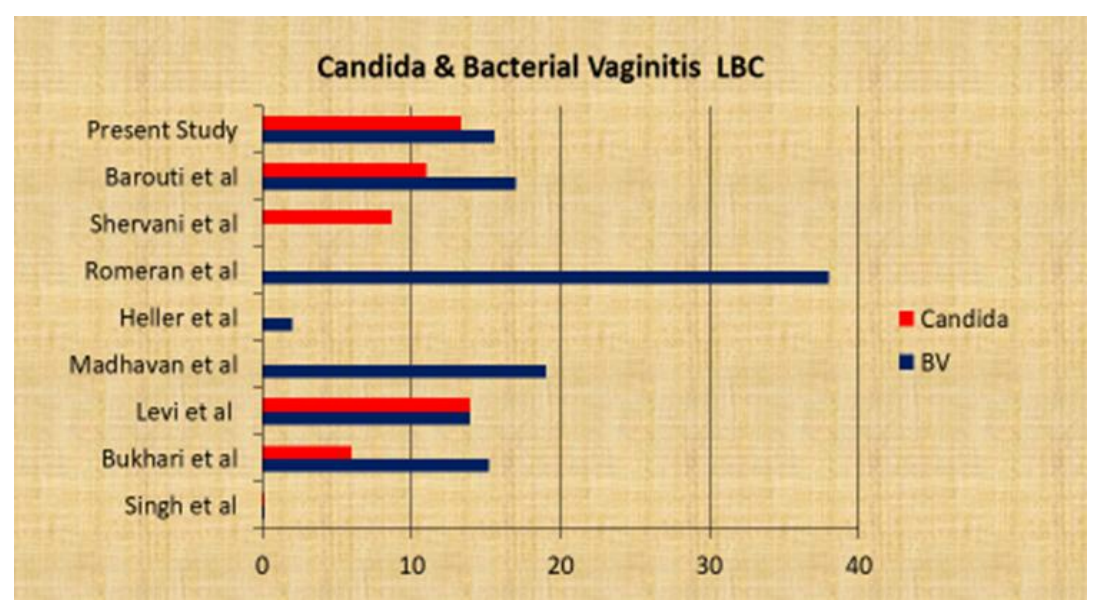

Finally LBC has a detection percentage lower for Bacterial Vaginitis, higher detection percentage for Herpes Simplex Virus, Leptothrix organisms, Candida and Trichomonas Vaginalis.

Conclusion: In our study we have seen that among cervicovaginal infections $\mathrm{BV}$ is the most common inflammatory disease and more easily detected on CPS compared to LBS. On the other hand Candidal Hyphae are more easily detected on LBS rather that CBS but spores of Candida can be easily washed away in the processing stages of LBC and therefore may be missed.

Trichomonas was more easily detected on LBS, similarly Leptothrix and the ground glass inclusions in Herpes Simplex virus.

Shift of Vaginal flora was detected more easily on conventional Pap smears than on Liquid based thinlayer preparations.

Diagnostic accuracy of liquid based cytology over conventional Pap smear has been studied in comparative studies focusing on improvement of diagnostic accuracy. Switching over to LBS from CPS should be considered keeping in mind all socioeconomic fractions of the global village. We found each method to have different capabilities as diagnostic tools in common cervicovaginal infections.

Approval has been taken from Ethics committee Dr. Ramesh Hospitals Vijayawada/Guntur.

\section{Acknowledgements: Nil}

Funding: Nil

\section{Competing Interests: Nil}

\section{References}

1. Chinaka CC, Abudullahi M, Mohammed OM. A comparative study on the use of Liquid Based Cytology and Conventional Pap Smear in cervical Screening. JJMR 2014;2:40-50.

2. Moriarty AT, Clayton AC, Zaleski S, Henry MR, Schwartz MR, Eversole GM et al. Unsatisfactory reporting rates: 2006 practices of participants in the college of American pathologists interlaboratory comparison program in gynecologic cytology. Arch Pathol Lab Med 2009;133:1912-16.

3. Takei H, Ruiz B, Hicks J. Cervicovaginal flora: comparison of conventional pap smears and a liquidbased thin-layer preparation. Am J Clin Pathol 2006;125:855-9. 
4. Fremont- Smith M, Marino J, Griffin B, Spencer L, Bolick D. Comparison of the SurePath liquid-based Papanicolaou smear with the conventional Papanicolaou smear in a multisite direct-to-vial study. Cancer 2004;102:269-79.

5. Dupree WB, Suprun HZ, Beckwith DG, Shane JJ, Lucente $\mathrm{V}$. The promise and risk of a new technology. Cancer 1998;84:202-7.

6. Singh VB, Gupta N, Nijhawan R, Srinivasan R, Suri V, Rajwanshi A. Liquid-based cytology versus conventional cytology for evaluation of cervical Pap smears: Experience from the first 1000 split samples. Indian $J$ Pathol Microbiol 2015;58:17-21.

7. Sakamoto H, Takenaka M, Ushimaru K, Tanaka T. Use of Liquid-Based Cytology (LBC) and Cell Blocks from Cell Remnants for Cytologic, Immunohistochemical, and Immunocytochemical Diagnosis of Malignancy. Open Journal of Pathology 2012;2:58-65.

8. Raina A, Rawat A, Nasreen K, Talib VH, Tayal U. Pap Smears in the Diagnosis of Bacterial Vaginosis. Indian Medical Gazette 2013;147:417-19.

9. Roeters AM, Boon ME, van Haaften M, Vemooji F, Bontekoe TR, Heintz AP. Inflammatory events as detected in cervical smears and squamous intraepithelial lesions. Diagn Cytopathol 2010;38:85-93.

10. Bukhari MH, Majid M, Qamar S, Niazi S, Syed SZ, Yusuf AW, et al. Clinicopathological study of Papanicolaou (Pap) smears for diagnosis of cervical infections. Diagn Cytopathol 2011;40:35-41.
11. Sherwani RK, Khan T, Akhtar K, Zeba A, Siddiqui FA, Rahman K, Afsan N. Conventional Pap smear and liquid based cytology for cervical cancer screening - a comparative study. J Cytol 2007;24:167-72.

12. Levi AW, Harigopal M, Hui P, Schofield K, Chhieng DC Comparison of Affirm VPIII and apanicolaou tests in the detection of infectious vaginitis. Am. J. Clin. Pathol 2011;135:442-7.

13. Madhivanan P, Krupp K, Chandrasekaran V, Karat C, Arun A, Cohen C. Prevalence and correlates of bacterial vaginosis among young women of reproductive age in Mysore, India. Indian J Med Microbiol 2008;26:132-7.

14. Heller DS, Maslyak S, Skurnick J. Is the presence of Trichomonas on a Pap smear associated with an increased incidence of bacterial vaginosis? J Low Genit Tract Dis. 2006;10:137-9.

15. Romoren M, Velauthapillai M, Rahman M, Sundby J, Klouman E, Hjortdahl P. Trichomoniasis and bacterial vaginosis in pregnancy: inadequately managed with the syndromic approach. Bull World Health Organ 007;85:297-304.

16. Barouti E, Farzaneh F, Sene A, Tajik Z, Jafari B. The pathogenic microorganisms in papanicolaou vaginal smears and correlation with inflammation. J Family Reprod Health 2013;7:23-7. 